\section{The quality of healthcare}

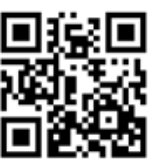

The quality of healthcare provided by a healthcare system is not always easily assessed. How can one assess the smile of reassurance from a nursing sister or the feeling of satisfaction of a patient when visiting a doctor in a resource-limited setting? There are, however, some objective measures of healthcare activity. In the case of obstetrics there is perinatal mortality. This can be adjusted to compensate for the rate of premature birth, and then expressed as the perinatal care index. Maternal mortality is another yardstick of care in obstetrics and that part of gynaecology that deals with early pregnancy.

The Millennium Development Goals were established on just this basis - that measures of mortality were a meaningful expression of the quality of life that a government could offer a population and the quality of medical care that is provided.

As well as providing simple numbers to enable one hospital, region or nation to compare itself with another, or with itself over time, it is also essential that each case of mortality is evaluated internally or externally to assess whether there are correctable deficiencies that may relate to patient activity, or the adequacy/ inadequacy of infrastructure, or the performance of medical staff. It is on this basis that nations have established Confidential Enquiries.

Not everything relates to mortality. Maternal morbidity can be monitored in 'near-miss' assessment, for which there is growing agreement of specific criteria in terms of intensive care admission, massive transfusion, need for hysterectomy, etc., since there are many disasters that can happen before the point of mortality is reached. As with mortality, near-miss assessment should focus on avoidable factors that can be addressed to improve care.

All of these measures can be an indication of the poor quality or good quality of the general health of the population that accesses a healthcare system, affected by levels of nutrition, living standards and sanitation, or can represent adequate or inadequate healthcare once the patient has arrived at the clinic or hospital door.

In the field of gynaecology, away from pregnancy, much of medical care and its impact are more difficult to measure. How does one reliably assess the accuracy of diagnosis or management of pelvic inflammatory disease, endometriosis or heavy menstruation, or even assess the provision of contraception? One exception to this in gynaecology is oncology. In gynaecological oncology, survival and mortality, if statistics are available, provide an index of care. Patients with certain stages of cancer have an internationally defined rate of cure or death.

But retrieval and recording of information is not always as easy in the developing world, from which much of the audience and many of the contributors to this journal come. Once treated, patients, who may have limited resources, have difficulty returning, and knowledge of outcome is lost. Yet there is care in these countries, sometimes better, sometimes worse; sometimes better resourced, sometimes not.

One concern in the developing world is the loss of resources that are available. These resources may be lost through bad management, poor infrastructure maintenance, needless expense, or the dreaded epidemic of corruption.

An article in this journal (Lohlun et al..$^{[1]}$ ) deals with the growing failure of a radiotherapy unit in Johannesburg, South Africa, to match international standards. The outcome is not measured in mortality; those statistics, for reasons given, are not available, but in the upstaging of patients as treatment is delayed.

Many countries in our region do not have radiotherapy services, or in some cases do not have primary healthcare, and yet some of these countries do have resources. Unless every attempt is made to gather data, lobby concerned roleplayers and publicise deficiencies, the situation will not improve. If these efforts are made, perhaps it will.

\section{William Edridge}

Editor

william.edridge@gmail.com 1. Lohlun KN, Kotzen JA, Lakier R. A prospective study on the impact of waiting times for
radiotherapy for cervical cancer at Charlotte Maxeke Johannesburg Academic Hospital. S Afr J
Obstet Gynaecol 2015;21(1):6-9. [http://dx.doi.org/10.7196/SAJOG.985]

S Afr J Obstet Gynaecol 2015;21(1):2. DOI.10.7196/SAJOG.1001 


\section{$11^{\mathrm{TH}}$ BIENNIAI}
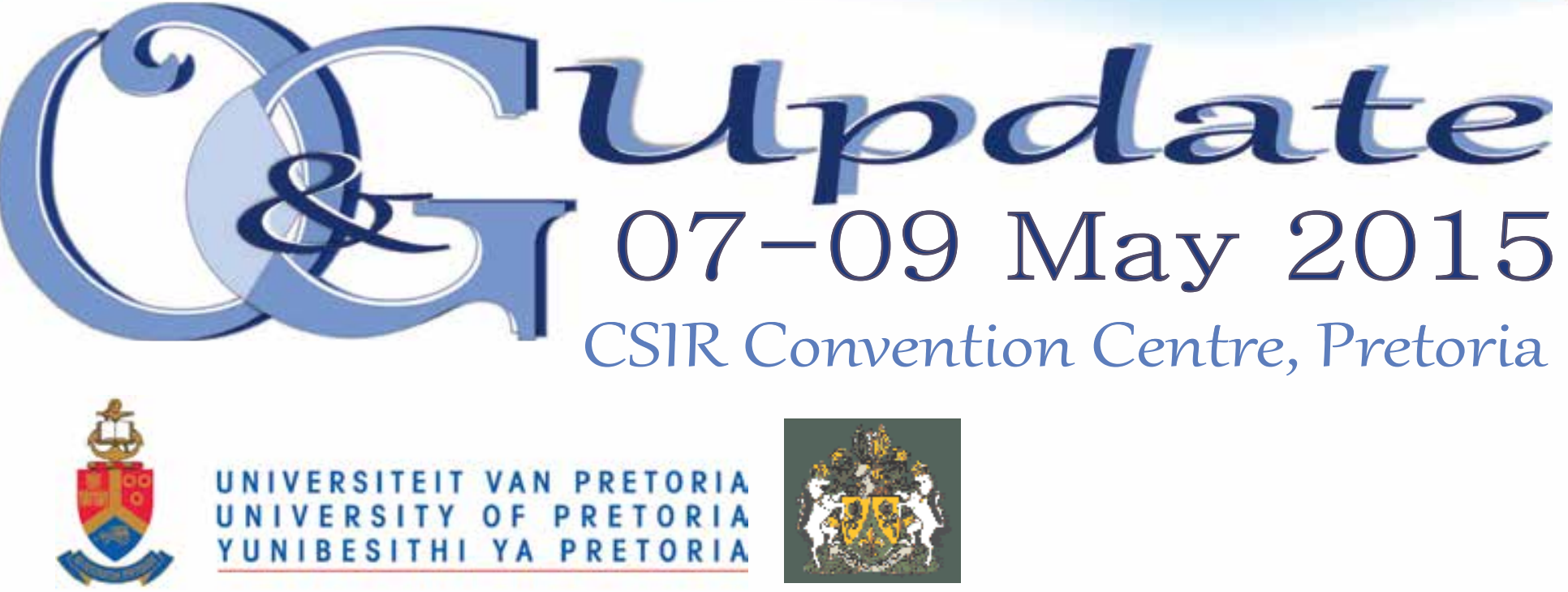

UNIVERSITEIT VAN PRETORIA

UNIVERSITY OF PRETORIA

YUNIBESITHI YA PRETORIA

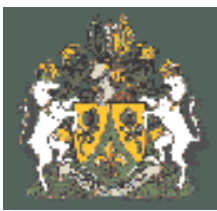

Congress Organisers

Londocor Event Management

Yvonne Fernandes

E-mail: yvonne@londocor.co.za OR Tel: + 27119545753 